REVISTA DE DERECHO UNED, núm. 4, 2009

\title{
FORO DE CONVENIENCIA, DERECHO DE CONVENIENCIA Y NULIDAD
}

\author{
FERNANDO REINOSO BARBERO \\ Catedrático de Derecho Romano de la Universidad Complutense. \\ Abogado
}

Resumen: Estudia los problemas actuales que plantean los fueros alternativos a la regla actor rei forum sequitur, en cuanto no son coincidentes en el derecho comunitario y en el interno español. En el derecho comunitario, las dificultades se concentran en la diferente interpretación que merecen las excepciones de competencia especial frente a las de competencia exclusiva, a fin de evitar el forum-shopping y otros accidentes procesales indeseables. En el derecho español, el problema se detecta en la distinción entre los efectos de los dos tipos de normas que regulan la competencia territorial, esto es, las imperativas y las dispositivas, que ha generado una verdadera disfunción en la jurisprudencia del Tribunal Supremo hasta el punto de aplicar analógicamente a los fueros improrrogables de competencia territorial normas que protegen exclusivamente la competencia objetiva.

Palabras clave: competencia territorial, fueros territoriales, competencias especiales, competencias exclusivas, competencias subordinadas, reserva de competencia, competencia improrrogable, forumshopping, law-shopping.

Abstract: Study the current problems thrown up by the alternative forums to the rule actor rei forum sequitur, as far as they are not coincident with communitarian and internal Spanish law. In communitarian law, difficulties concentrate in the different interpretation which exceptions of competence deserve versus those 
of exclusive competence, in order to avoid 'forum-shopping' and other undesirable procedural accidents. In Spanish law, the problem is detected in the distinction between the effects of the two types of rules that regulate the territorial competence, i. e., the imperatives and dispositions generated by a true malfunction in the jurisprudence to the point of applying rules that protect the objective competition analogically to the imperative territorial forums.

Key words: territorial competence, territorial privileges, special competences, exclusive competences, subordinate competences, reserve of competence, un-extendable competence, forum-shopping, law-shopping.

Sumario: 1. El problema: las normas de conflicto aplicables.-2. El régimen general: 'actor rei forum sequitur'.-3. Excepciones en el derecho Romano.-4. Excepciones en el derecho comunitario.-5. Excepciones en el derecho español.-6. Una posible solución.

\section{EL PROBLEMA: LAS NORMAS DE CONFLICTO}

El problema aún no se ha hecho completamente perceptible en España. $\mathrm{O}$ al menos no en toda su dimensión. Resulta inevitable que el principio de primacía - el denominado efecto inclinado- del derecho comunitario sobre el interno de los Estados miembros de la UE, introduzca un profundo cambio en el panorama que tradicionalmente ha informado la discusión sobre la competencia territorial en España.

Siempre se ha partido de un hecho que, en buena medida, ha dejado de ser cierto: la competencia territorial era una mera consecuencia de la organización de la planta judicial del Estado, que no afectaba al derecho aplicable pues, en todo caso, éste era garantizado por la intervención de un juez con competencia objetiva. En otras palabras, la resolución previsible debía ser similar tanto procediera de un órgano territorialmente competente como incompetente, siempre que lo fuera objetiva y funcionalmente. Por esta razón, entre otras derivadas directa o indirectamente de ella, la incompetencia territorial ha tenido y tiene en nuestro derecho una 'sanción' de menor entidad que la incompetencia objetiva. Baste pensar que mientras esta última es causa de nulidad radical (arts. 48 y 225.1 LEC y 238.1 LOPJ), la primera no lo es ni tan siquiera en los supuestos de improrrogabilidad impuestos por normas imperativas. 
Sin embargo, hoy, debe tenerse en cuenta que la Constitución ha definido un nuevo sistema de fuentes formales del derecho derivado de dos parámetros: la incorporación del derecho comunitario europeo (art. $93 \mathrm{CE}$ ) y la configuración del Estado autonómico. Ambos afectan de forma trascendente, uno por arriba y otro por abajo, a la competencia territorial tal como hasta ahora es concebida. Por eso creo razonable el replantearse alguno de los dogmas que suelen dominar los debates sobre ella. De forma muy especial el verdadero alcance exegético que debe tener su carácter dispositivo básico, y la protección procesal dispensable a las normas que lo excluyen.

La actual imbricación de España dentro de la estructura competencial decidida por la normativa de la UE provoca numerosas consecuencias, que deberían conducir a un nuevo examen de nuestro sistema. Aún si prescindimos de sus efectos más obvios, hay que reconocer que la competencia territorial ha dejado de ser un simple resultado de demarcación interna. El nuevo escenario es diseñado por los arts. 3 y ss del Reglamento CE n. ${ }^{\circ} 44 / 2001$ del Consejo, de 22 de diciembre de 2000, y por el Convenio de Lugano de 30 de octubre de 2007, relativos a la competencia judicial, el reconocimiento y la ejecución de resoluciones judiciales en materia civil y mercantil. Y, sobretodo, la realidad es que el derecho aplicable puede llegar a ser condicionado por el órgano judicial que conozca del caso, dado que las normas de conflicto para determinarlo serán las del juez ante el que se plantee. De hecho, ya no se puede desconocer que la búsqueda del fuero de conveniencia (forum-shopping) persigue en la mayoría de las ocasiones aplicar un derecho de conveniencia (law-shopping). Incluso en el ámbito penal (ajeno a estas líneas, que se circunscriben preferentemente a la jurisdicción civil y mercantil), el propio TS, en la extensa Sentencia de 17 de julio de 2008, demanda una profunda armonización del derecho procesal para evitar el forum-shopping ${ }^{1}$. La Sala de lo Civil del $\mathrm{TS}^{2}$ ha utilizado también ese término, acuñado en el derecho estadounidense, y lo considera un fraude vinculado a otro consistente en forzar la ley aplicable.

Hay que añadir que en la actualidad, en los casos en los que se ha excluido el exequátur, ha desaparecido con él la verificación que los

${ }^{1}$ STS 2. a 503/2008 de 17.07.2008, FJ 6 (p. 455): «En realidad, una rigidez internacional de la prohibición del bis in idem en esos casos, pareja a la existente en el marco interno, requeriría probablemente una previa armonización, en algunos casos profunda, del Derecho Penal y Procesal Penal de los Estados afectados, que suprima las diferencias sustanciales en la respuesta penal a determinados tipos delictivos y al tiempo impida el forum shopping».

${ }^{2}$ ATS 1. ${ }^{a}$ 1345/1999 de 02.02.1999, FJ 7. 
órganos jurisdiccionales españoles aplicaban al efecto al conceder ejecutoriedad a resoluciones de tribunales extranjeros. Desde el Consejo Europeo de Tampere el principio de reconocimiento mutuo de resoluciones judiciales es la raíz del espacio judicial europeo y «piedra angular» de la cooperación judicial en la UE. Ya no se requiere un proceso que filtre o compruebe si ha existido búsqueda fraudulenta del fuero en el que se dicta la resolución que se va a ejecutar en España. Tampoco es necesario cotejar la conformidad de la resolución con el ordenamiento jurídico Español. El vigente sistema conduce a su ejecución casi automática. Al tiempo de escribir estas páginas, la última manifestación de este nuevo régimen la aporta la Ley $1 / 2008$, de 4 de diciembre, para la ejecución en la UE de resoluciones que impongan sanciones pecuniarias ${ }^{3}$, y su complementaria Ley Orgánica 2/2008, de esa misma fecha, por la que se modifican los preceptos correspondientes de la $\mathrm{LOPJ}^{4}$.

Los cuerpos legales atribuyen al juez de cualquier Estado miembro de la UE, y demás vinculados convencionalmente con ella en esta materia, la responsabilidad de establecer, conforme a sus propias normas de conflicto, la ley que resulte aplicable a la obligación de la que derive el proceso en cuestión. El forum-shopping y el law-shopping son prácticas ya detectadas y constatadas que demuestran la envergadura del problema, en las que el demandante elige el juez en atención a los beneficios que le reporta la ley aplicable que aquél impondrá. Pero son solo parte del problema, en el que subyacen otros numerosos aspectos.

Esa realidad, constatada en el plano supranacional, podría quizás presentarse también - aunque sea con diferentes matices- en el plano 'infranacional' como consecuencia de la creciente y voraz promiscuidad de las legislaciones autonómicas dentro de España. Es cierto que aquí el problema siempre será extraordinariamente menor dada la uniformidad de las «normas para resolver los conflictos de leyes» que son competencia exclusiva del Estado (art. 149.1.8 ${ }^{\circ} \mathrm{CE}$ ). Uniformidad que, sin embargo, no existe en el plano supranacional. Pero la configuración constitucional interna del Estado implica que las normas puedan proceder tanto de los órganos estatales como de las Comunidades autónomas. Si bien la Constitución atribuye al Estado la competencia exclusiva sobre «la determinación de las fuentes del Derecho", sin embargo, tal competencia se asigna a la respectiva Comunidad Autónoma respecto de las fuentes de los derechos civiles

\footnotetext{
${ }^{3}$ BOE núm. 293, 5 diciembre 2008, 48679.

${ }^{4}$ BOE núm. 293, 5 diciembre 2008, 48678.
} 
forales. Ésta es la interpretación que se deduce del art. 149.1.8 $\mathrm{CE}$ pues, tras declarar la autoridad del Estado respecto de la legislación civil, añade que «sin perjuicio de la conservación, modificación y desarrollo por las Comunidades autónomas de los derechos civiles, forales o especiales, allí donde existan». El mismo precepto, al final, reitera esta dualidad al ordenar que la facultad estatal sobre la determinación de las fuentes se ejerza «con respeto» a las normas de derecho foral o especial.

Tal cúmulo de circunstancias, junto con otras que mencionaré más adelante, han alterado el marco en el que se desenvolvía la competencia territorial y sugieren su revisión.

\section{EL RÉGIMEN GENERAL: 'ACTOR REI FORUM SEQUITUR'}

La regla procedente del derecho romano actor rei forum sequitur ${ }^{5}$ impone al actor el fuero territorial del domicilio del demandado. Constituye hoy un principio general tanto del derecho español como del comunitario de la UE. Pero la creciente complejidad de las relaciones jurídicas actuales origina que, para casos concretos, las legislaciones prevean, cada vez con más intensidad, reservas de competencia a favor de fueros alternativos. Sobre todo en el ámbito del conflicto supranacional en materia civil y mercantil, donde no terminan de cristalizar completamente las pautas que deben regir la competencia judicial, lo que las somete a una constante evolución.

El Tribunal de Justicia de la UE, en numerosas sentencias, ha conferido a la regla actor rei forum sequitur el carácter de principio general. La justificación de su pervivencia, por lo demás obvia, es explicada en la STJUE del Pleno de 19 febrero 2002: facilita la defensa del demandado ${ }^{6}$. Si bien el propio Tribunal, en la STJUE de la Sala 6. ${ }^{\text {a de }} 13$ julio 2000, remarcó las excepciones restrictivas a este prin-

${ }^{5}$ Sobre este principio véase un resumen ejemplar en DOMINGO, ORTEGA, RODRIGUEZ-ANTOLÍN, y ZAMBRANA, Principios de derecho global. 1000 reglas y aforismos jurídicos comentados, Navarra, 2006, p. 47

${ }^{6}$ STJUE, Pleno, C-256/2000 de 19 febrero 2002: «En efecto, el sistema de atribución de competencias comunes establecidas en el título II del Convenio de Bruselas se basa en la regla general formulada en el artículo 2, párrafo primero, según la cual las personas domiciliadas en un Estado contratante estarán sometidas a los órganos jurisdiccionales de dicho Estado, con independencia de la nacionalidad de las partes. El carácter de principio general que reviste esta regla de competencia, que constituye la expresión del adagio actor sequitur forum rei, se explica por el hecho de que, en principio, permite al demandado defenderse más fácilmente». 
cipio en las que el demandado puede dejar de estar sometido a los órganos jurisdiccionales del Estado donde tiene su domicilio y ser demandado ante un tribunal de otro Estado ${ }^{7}$, cuando a la situación se le aplique una orden de competencia especial o una orden de competencia exclusiva o una prórroga de competencia.

Tanto el principio actor rei forum sequitur como sus excepciones ya estaban previstas en los antiguos Convenios de Bruselas ${ }^{8}$ de 27 de septiembre de 1968 y de Lugano $^{9}$ de 16 de septiembre de 1988, cuya configuración actual se recoge en el Reglamento ${ }^{10}$ n. ${ }^{\circ} 44 / 2001$ del Consejo, de 22 de diciembre de 2000, y en el Convenio ${ }^{11}$ de 30 de octubre de 2007, todos ellos relativos a la competencia judicial, el reconocimiento y la ejecución de resoluciones judiciales en materia civil y mercantil. Cabría añadir todavía algunos documentos importantes, en materias específicas, especialmente sobre competencia judicial en el ámbito de la responsabilidad parental (existe una Propuesta de Reglamento del Consejo, de 17 de julio de 2006, por el que se modifica el Reglamento $\mathrm{n}^{\circ} 2201 / 2003$ en lo que se refiere a la competencia judicial) o en el de las obligaciones contractuales, previstas en el reciente Reglamento 593/2008 del Parlamento Europeo y del Consejo de 17 de junio de 2008 sobre la ley aplicable a las mismas.

${ }^{7}$ STJUE, Sala 6. ${ }^{\text {a }}$ C-412/1998 de 13 julio 2000, en su numeral 35 dice: «El carácter de principio general que reviste esta regla de competencia, que constituye la expresión del adagio actor sequitur forum rei, se explica por el hecho de que, en principio, permite al demandado defenderse más fácilmente véase, en este sentido, la sentencia de 17 de junio de 1992, Handte, C-26/91, Rec. p. I-3967, apartado 14; véase igualmente el Informe del Abogado General Jenard relativo al Convenio de Bruselas (DO 1979, C 59, pp. 1 y ss., especialmente p. 18; texto en español, DO 1990, C 189, pp. 122 y ss., especialmente p. 138)». En el numeral 36 añade: «únicamente como excepción a este principio fundamental de la competencia de los órganos jurisdiccionales del Estado contratante en cuyo territorio el demandado tiene su domicilio o domicilio social, el Convenio prevé, conforme al artículo 3, párrafo primero, ciertos casos, enumerados restrictivamente en las Secciones 2 a 6 del Título II, en los que el demandado domiciliado o establecido en un Estado contratante puede, cuando a la situación se le aplique una regla de competencia especial, o debe, cuando a la situación se le aplique una regla de competencia exclusiva o una prórroga de competencia, dejar de estar sometido a los órganos jurisdiccionales del Estado donde tiene su domicilio y ser demandado ante un tribunal de otro Estado contratante». Finalmente en el numeral 37: «En este contexto, las Secciones 2 a 6 del Título II del Convenio contienen ciertas disposiciones especiales que, a efectos de determinar el órgano jurisdiccional competente, se separan del criterio general del domicilio del demandado y atribuyen con carácter excepcional una cierta influencia al domicilio del demandante».

${ }^{8}$ Versión consolidada en DO C 27 de 26.01.1998, p. 1 ss.

${ }^{9}$ DO L 319 de 25.11.1988, p. 9 ss.

${ }^{10}$ DO L 12 de 16.01.2001, p. 1.Versión consolidada en DO L 5 de 01.01.2007, p. 1

${ }^{11}$ DO L 339 de 21.12.2007, p. 3 ss. 
Cuando esas u otras normas atribuyan la competencia a los órganos judiciales españoles deberán ser aplicadas en conexión con lo previsto en los arts. 22 LOPJ y 50 y ss. LEC. El primer precepto estudia los supuestos en los que los órganos jurisdiccionales españoles son o pueden ser competentes, mientras que la designación del tribunal específico competente dentro de España se determina conforme a las normas contenidas en los segundos.

Expondré a continuación los problemas más graves que, a mi juicio, plantean los fueros alternativos a la regla actor rei forum sequitur, en cuanto no son coincidentes en el derecho comunitario y en el interno español. En el derecho comunitario, las dificultades se concentran en la diferente interpretación que merecen las excepciones de competencia especial frente a las de competencia exclusiva, a fin de evitar el forumshopping y otros accidentes procesales indeseables. En el derecho español, el problema se detecta en la distinción entre los efectos de los dos tipos de normas que regulan la competencia territorial, esto es, las imperativas y las dispositivas, que ha generado una verdadera disfunción en la jurisprudencia del TS hasta el punto de aplicar analógicamente a los fueros improrrogables de competencia territorial normas que protegen exclusivamente la competencia objetiva.

\section{EXCEPCIONES EN EL DERECHO ROMANO}

El principio actor rei forum sequitur procede del derecho romano. Ha sido tomado literalmente ${ }^{12}$ de una constitución de los emperadores Valentiniano, Teodosio y Arcadio del año 385, recogida por el CI $3,19,3$.

Ya antes, en el derecho clásico, hay fuentes que señalan la competencia territorial del magistrado de la «ciudad» del demandado. Ésta se colige tanto del lugar de nacimiento como del domicilio actual. Ulpiano dice en el libro tercero de sus comentarios al edicto, que se concede el derecho a ser juzgado en su ciudad de origen a los que se hallan en una legación fuera de ella ${ }^{13}$. El jurista añade que son «juzgados en su ciudad de origen todos aquellos que no celebraron el negocio que da lugar al pleito donde son demandados; pero si lo celebraron allí, no tienen derecho a ser juzgados en otra

${ }^{12}$ Actor rei forum, sive in rem sive in personam sit actio, sequitur.

${ }^{13}$ D. $5,1,2,3$. 
parte» ${ }^{14}$. En caso de duda, se atribuye al magistrado la capacidad de resolverla ${ }^{15}$.

La circunstancia de que los textos jurisprudenciales se refieran a las «personas que tienen derecho a ser juzgados en su ciudad ${ }^{16}$ evidencia la existencia de otros casos a los que no afecta la regla, y que se hacen más evidentes en el derecho postclásico y justinianeo. Así, una constitución de Antonino ${ }^{17}$ del año 214 admite el fuero elegido de común acuerdo por las partes. Otra de los emperadores Diocleciano y Maximiano ${ }^{18}$ del 287-304, establece la competencia del lugar del domicilio que tenía el demandado cuando hizo el contrato. En este caso se puede invertir el orden, de suerte que el actor no siga el fuero del reo, sino el reo el del actor. Sucesivas constituciones implantan excepciones especiales de competencia: la de Severo y Antonino ${ }^{19}$ del año 196 complementa el forum delicti commissi con el de la ciudad donde son hallados aquellos a quienes se les acusa de ser reos del crimen, y otra ${ }^{20}$ de los mismos emperadores señala la jurisdicción del lugar donde se dejó la herencia para conocer de la petición de fideicomiso; la de Valeriano y Galieno ${ }^{21}$ del año 260 ordena que la acción de herencia se ejercite en el domicilio del demandado, sin perjuicio de que la posesión de los bienes hereditarios se pida donde éstos se encuentren; la de Diocleciano y Maximiano ${ }^{22}$ del año 292 sobre la acción de rendición de cuentas contra el que administró negocios ajenos, que ha de ejercitarse donde los administró; la de Valentiniano y Valente ${ }^{23}$ del año 366, relativa a la acción de posesión que corresponde al lugar donde estén los bienes que se pretende poseer; la de Valentiniano, Teodosio y Arcadio ${ }^{24}$ del año 385, sobre el forum rei sitae: la acción real se puede ejercitar en el lugar en el que se hallan los bienes; etc.

${ }^{14}$ D. $5,1,2,4$.

${ }^{15}$ D. $5,1,2,6$.

${ }^{16}$ D. 5,1,5, Ulpiano libro quinto ad edictum: «Si quis ex aliena iurisdictione ad praetorem vocetur, debet venire, ut et Pomponius et Vindius scripserunt: praetoris est enim aestimare, an sua sit iurisdictio, vocati autem non contemnere auctoritatem praetoris: nam et legati ceterique qui revocandi domum ius habent in ea sunt causa, ut in ius vocati veniant privilegia sua allegaturi».

${ }^{17}$ CI. $3,13,1$.

${ }^{18}$ CI. $3,13,2$.

${ }^{19}$ CI. $3,15,1$.

${ }^{20}$ CI. $3,17,1$.

${ }^{21}$ CI. $3,20,1$.

${ }^{22}$ CI. $3,21,1$.

${ }^{23}$ CI. $3,16,1$.

${ }^{24}$ CI. $3,19,3$. 
Con estos datos solo quiero dejar constancia de un hecho: desde el origen romano de nuestra tradición jurídica se han reglado excepciones al fuero general. Además, como en seguida se verá, esas excepciones se corresponden básicamente con las actuales.

\section{EXCEPCIONES EN EL DERECHO COMUNITARIO}

El artículo 220 del Tratado CE dispone que «los Estados miembros entablarán, en tanto sea necesario, negociaciones entre sí, a fin de asegurar en favor de sus nacionales: ... la simplificación de las formalidades a que están sometidos el reconocimiento y la ejecución recíprocos de las decisiones judiciales y de los laudos arbitrales». Uno de los resultados más importantes de tal compromiso fue el Convenio de Bruselas de 27 de septiembre de 1968. El art. 2 de ese Convenio consagró el principio actor rei forum sequitur al tiempo que estableció sus excepciones en los preceptos siguientes. Éstas están constituidas tanto por las denominadas competencias 'especiales' como por las 'exclusivas' y han evolucionado cuantitativa y cualitativamente desde que fueron establecidas en aquel Convenio. La última fase de su génesis, como ahora se verá, se encuentra en el texto del Convenio de Lugano 30 de octubre de $2007^{25}$. Concretamente en sus artículos 5 y ss. (competencia especial), 22 (competencia exclusiva) y 23 (prórroga de competencia).

Pero entre uno y otro texto existe toda una extensa historia de instrumentos que tratan las excepciones al fuero general, que da lugar a la Decisión del Consejo, de 15 de octubre de 2007, relativa a la firma, en nombre de la Comunidad, del Convenio sobre la competencia judicial, el reconocimiento y la ejecución de resoluciones judiciales en materia civil y mercantil ${ }^{26}$. En su numeral 1 recuerda que el 16 de septiembre de 1988, se suscribió el Convenio de Lugano, por el que se ampliaba más allá de la $\mathrm{UE}^{27}$ la aplicación de las normas del Convenio de Bruselas relativo a aquella materia ${ }^{28}$. Con fundamento en dicho texto el Consejo adoptó el Reglamento (CE) n. ${ }^{\circ} 44 / 2001$ (en ade-

${ }^{25}$ En particular su Protocolo n. ${ }^{\circ} 1$ relativo a determinados problemas de competencia, procedimiento y ejecución. El Protocolo n. ${ }^{\circ} 2$ es relativo a la interpretación judicial uniforme del Convenio y al Comité permanente.

${ }^{26}$ 2007/712/CE publicada en el DO L 339 de 21.12.2007, p. 1 y ss..

${ }^{27}$ Concretamente a Islandia, Noruega y Suiza.

${ }^{28}$ Información relativa a la fecha de entrada en vigor del Acuerdo entre la Comunidad Europea y el Reino de Dinamarca relativo a la competencia judicial ha sido publicada en el DO L 4M de 8.1.2008, p. 324 y 324. 
lante 'el Reglamento') «que modernizó las normas del Convenio de Bruselas y ha hecho más ágil y eficaz el sistema de reconocimiento y ejecución» ${ }^{29}$. En realidad el Reglamento modifica y sustituye a éste, por lo que se hizo conveniente ajustar las normas del Convenio de Lugano a las del Reglamento, lo que dio lugar al actual Convenio de Lugano de 30 de octubre de 2007 (en adelante 'el Convenio'). Aunque el contenido del Convenio no es idéntico al del Reglamento, su articulado guarda la misma numeración, que, sin embargo, se separa de la de Bruselas a partir del artículo 7.

Es indispensable advertir que el propio principio actor rei forum sequitur y parte de sus excepciones previstas hoy en el Reglamento y en el Convenio coinciden con las del Convenio de Bruselas, por lo que los comentarios doctrinales y la jurisprudencia son perfectamente extrapolables. Esta realidad es reconocida en Conclusiones de varios Abogados Generales, entre las que destaca las presentadas el 14 de marzo de 2006 en el Asunto C-103/05 2 .

El Reglamento pretende que las reglas de competencia judicial presenten un alto grado de previsibilidad a partir del principio actor rei forum sequitur. El Reglamento afirma que «la competencia judicial se basa generalmente en el domicilio del demandado y esta competencia debe regir siempre, excepto en algunos casos muy concretos en los que la materia en litigio o la autonomía de las partes justifique otro criterio de vinculación» ${ }^{31}$.

Los fueros alternativos que excepcionan la regla actor rei forum sequitur, previstos tanto en el Reglamento como en el Convenio, se configuran en la actualidad en términos restrictivos. Uno y otro, en sus respectivos art. 2.1, comienzan por proclamar el principio actor rei forum sequitur y se valen de una expresión similar a la de su antecedente de Bruselas ${ }^{32}$, para a continuación, en su art. 3.1, permitir

${ }^{29}$ Numeral 3 de la Decisión antes mencionada de 15.10.2007.

30 Asunto C-103/05, Reisch Montage AG contra Kiesel Baumaschinen Handels GMBH, que resuelve la petición de decisión prejudicial planteada por el Oberster Gerichtshof de la República de Austria. Cfr. en concreto la conclusión 18.

${ }^{31}$ Reglamento 44/2001, considerando 11.

${ }^{32}$ Las únicas diferencias entre los tres casos son que el primero (Bruselas) no divide el artículo en números y la referencia a los Estados contratantes (Bruselas), miembros (Reglamento) y vinculados (Convenio). Con esas diferencias mínimas, el artículo 2.1 dispone: «Salvo lo dispuesto en el presente Convenio, las personas domiciliadas en un Estado vinculado por el presente Convenio estarán sometidas, sea cual fuere su nacionalidad, a los órganos jurisdiccionales de dicho Estado». Este precepto responde a la idea sentada en el Considerando 8 del Reglamento: «Los litigios a los que se aplica el presente Reglamento deben presentar un nexo con el territorio de los 
excepcionalmente que las personas puedan ser demandadas ante los tribunales de otro Estado solo «en virtud de las reglas establecidas en las secciones 2 a 7 del presente título». En esas secciones se regulan, respectivamente, las competencias: especiales (arts. 5-7), en materia de seguros (arts. 8-14), en materia de contratos celebrados por los consumidores (arts. 15-17), en materia de contratos individuales de trabajo (arts. 18-21), exclusivas (art. 22) y prórroga de competencia (arts. 23-24). Estas excepciones pueden reducirse a las competencias especiales y a las exclusivas, pues las materias de seguros, consumo y trabajo pertenecen a las primeras y la prórroga de competencia a las segundas.

La diferencia fundamental entre las excepciones especiales y las exclusivas radica en que mientras éstas sustituyen el fuero del domicilio del demandado, aquéllas lo complementan en el sentido de que permiten al actor optar entre el fuero general (actor rei forum sequitur) o el especial. El contenido de los fueros alternativos es el siguiente:

A. Con carácter especial: las materias previstas en los arts. 5 al 21 del Reglamento y del Convenio, esto es, la contractual, de alimentos, delictual o cuasidelictual ${ }^{33}$, de acciones por daños y perjuicios, litigios relativos a la explotación de sucursales o establecimientos, trust, salvamento de cargamentos o de fletes, seguros, consumo y contratos de trabajo. En todos estos casos puede ejercitarse la acción en un lugar diferente al del domicilio del demandado. Las razones que justifican realizar estas salvedades son expuestas en el Reglamento: «El fuero del domicilio del demandado debe completarse con otros fueros alternativos a causa del estrecho nexo existente entre el órgano jurisdiccional y el litigio o para facilitar una buena administración de justicia ${ }^{34} »$. En la práctica, los motivos que amparan los fueros alternativos se pueden reconducir a la primacía de dos ideas: $1 .^{\circ}$ ) por pura funcionalidad, a

Estados miembros sujetos a dicho Reglamento. Por consiguiente, las reglas comunes sobre competencia judicial se aplicarán, en principio, cuando el demandado esté domiciliado en uno de dichos Estados miembros». El Considerando siguiente aclara que los demandados no domiciliados en un Estado miembro quedan sujetos a las reglas nacionales de competencia aplicables en el territorio del Estado miembro del tribunal ante el que se presente la demanda. Sin embargo los demandados domiciliados en un Estado miembro no sujeto al Reglamento deberán seguir estando sujetos al Convenio de Bruselas.

${ }^{33}$ La jurisprudencia del TJUE entiende por «obligaciones en materia delictual o cuasidelictual» las reclamaciones «dirigidas a exigir la responsabilidad de un demandado y que no están relacionadas con la 'materia contractual' en el sentido del artículo 5, número $1 »$.

${ }^{34}$ Reglamento 44/2001, considerando 12. 
fin de facilitar al órgano competente la consecución de la pretensión procesal, por su 'conexión relevante' con el caso o, según las condiciones, por la utilidad de su competencia respecto de la prueba y de la sustanciación del proceso. Es el supuesto, por ejemplo, de las obligaciones contractuales (en las que se podrá optar por el fuero del lugar de cumplimiento de la obligación), o de las acciones por daños y perjuicios (que se podrán ejercitar en el lugar en que se hayan causado), o litigios relativos a la explotación de sucursales, agencias y establecimientos (que podrán promoverse donde éstos se encuentren); $2 .^{\circ}$ ) por una tendencia tuitiva que pretende facilitar la defensa procesal de los intereses aparentemente más débiles: así, bajo determinadas circunstancias, el actor podrá demandar en su propio domicilio cuando reclame alimentos. Otro tanto sucede en materias relativas a contratos de seguro, consumo y trabajo, cuando el demandante es el asegurado, consumidor o empleado. Concretamente, en materia de contrato de seguro, la sentencia ${ }^{35}$ de la Sala Segunda del TJUE de 13 de diciembre de 2007 ha extendido ciertas facultades del asegurado al perjudicado domiciliado en un Estado miembro, de forma que éste pueda entablar ante el tribunal del lugar de su domicilio una acción directa contra el asegurador, siempre que la acción directa sea posible y el asegurador esté domiciliado en un Estado miembro.

B. Con carácter exclusivo: las materias reguladas en los arts. 22 al 24 del Reglamento y del Convenio ${ }^{36}$, es decir, los derechos reales y contratos de arrendamiento de bienes inmuebles, algunos aspectos fun-

${ }^{35}$ Asunto C-463/06, FBTO Schadeverzekeringen NV contra Jack Odebreit, sobre petición de decisión prejudicial planteada por el Bundesgerichshof de Alemania.

${ }^{36} \mathrm{El}$ contenido de estos preceptos se corresponde con los arts. 16 al 18 del texto de Bruselas. El art. 22 del Convenio dispone: «Son exclusivamente competentes, sin consideración del domicilio: 1) en materia de derechos reales inmobiliarios y de contratos de arrendamiento de bienes inmuebles, los tribunales del Estado vinculado por el presente Convenio donde el inmueble se hallare sito. No obstante, en materia de contratos de arrendamiento de bienes inmuebles celebrados para un uso particular durante un plazo máximo de seis meses consecutivos, serán igualmente competentes los tribunales del Estado vinculado por el presente Convenio donde estuviere domiciliado el demandado, siempre que el arrendatario fuere una persona física y que arrendador y arrendatario estuvieren domiciliados en el mismo Estado vinculado por el presente Convenio; 2) en materia de validez, nulidad o disolución de sociedades y personas jurídicas, así como en materia de decisiones de sus órganos, los tribunales del Estado vinculado por el presente Convenio en que la sociedad o persona jurídica estuviere domiciliada; para determinar dicho domicilio, el tribunal aplicará sus reglas de Derecho internacional privado; 3) en materia de validez de las inscripciones en los registros públicos, los tribunales del Estado vinculado por el presente Convenio en que se encontrare el registro; 4) en materia de inscripciones o validez de patentes, marcas, diseños o dibujos y modelos y demás derechos análogos sometidos a depósito o registro, independientemente de que el asunto haya sido el resultado de una 
damentales de las personas jurídicas, inscripciones registrales, patentes, ejecución de resoluciones y la reserva de competencia por sumisión expresa, o también la tácita si bien solo en cuanto resulte de la perpetuatio competentiae. Puede decirse así que el forum domicilii es excluido tanto por razón de la materia como por voluntad de las partes ${ }^{37}$.

Con carácter general los fueros alternativos se excluyen entre sí, incluso dentro de la misma categoría. La sentencia ${ }^{38}$ de la Sala Primera del TJUE de 22 de mayo de 2008 decidió la incompatibilidad entre las reglas de competencia especial del art. 6.1 (forum connexitatis: si hubiere varios demandados, permite demandar ante el tribunal del domicilio de cualquiera de ellos) y la de los arts. 18 y ss. (contrato individual de trabajo) del Reglamento.

En el derecho comunitario la diferencia entre los fueros de competencia territorial especial y las de competencia territorial exclusiva recae, sobretodo, en la posibilidad que los primeros otorgan al actor de poder elegir el tribunal. La conclusión razonable de esta desigualdad impide que el régimen exegético de unos y otros pueda ser el mismo. La capacidad de elección del fuero - característica de las excepciones especiales- envuelve numerosos riesgos, en concreto el más obvio: que el demandante escoja el fuero del lugar cuyo derecho le sea más favorable o, lo que es lo mismo, el más perjudicial a los intereses del demandado, con lo que se puede incurrir en el supuesto conocido como forumshopping for lawshopping.

Como recuerda el Abogado General Geelhoed, en las Conclusiones ${ }^{39}$ presentadas el 31 de enero de 2002, las excepciones especiales al

acción o de la defensa, los tribunales del Estado sujeto al Convenio en que se hubiere solicitado, efectuado o tenido por efectuado el depósito o registro en virtud de lo dispuesto en algún convenio internacional o instrumento comunitario. Sin perjuicio de la competencia de la Oficina Europea de Patentes según el Convenio sobre la patente europea, firmado en Munich el 5 de octubre de 1973, los tribunales de cada Estado vinculado por el presente Convenio serán los únicos competentes, sin consideración del domicilio, en materia de registro o validez de una patente europea expedida para dicho Estado, independientemente de que el asunto haya sido el resultado de una acción o de la defensa; 5) en materia de ejecución de las resoluciones judiciales, los tribunales del Estado vinculado por el presente Convenio del lugar de ejecución».

${ }^{37} \mathrm{Cfr}$. conclusión 22 del antes citado Informe de 14 de marzo de 2006 en el Asunto $\mathrm{C}-103 / 05$.

${ }^{38}$ Sobre petición de decisión prejudicial planteada por la Cour de cassation francesa en el asunto Laboratoires Glaxosmithkline contra Jean-Pierre Rouard. DO C 171 de 05.07.2008, p. 7 ss.

${ }^{39}$ Asunto C-334/00, Fonderie Officine Meccaniche Tacconi Spa contra Heinrich Wagner Sinto Maschinenfabrik GMBH, que resuelve una petición de decisión prejudicial planteada por la Corte Suprema di Cassazione de Italia. 
principio actor rei forum sequitur deben interpretarse restrictivamente conforme a lo establecido por una jurisprudencia reiterada del TJUE. Es decir, estas excepciones no pueden extenderse por analogía a otros supuestos distintos ${ }^{40}$.

Sin embargo tal doctrina, fundada en causas de seguridad jurídica, debe ser compatible con la inexistencia en el derecho comunitario de una regla que imponga la interpretación restrictiva a todas las excepciones $^{41}$. De esta forma debe considerarse que el carácter restrictivo de la interpretación de los fueros alternativos alcanza a los del art. 5 del Reglamento y del Convenio, que son los susceptibles de generar el efecto indeseable del forum-shopping y law-shopping. En definitiva, la interpretación restrictiva persigue, entre otros resultados, evitar que el actor elija el tribunal no por la idoneidad de su competencia territorial, sino en atención a sus normas sobre conflictos de leyes en cuanto le resulten más favorables.

La interpretación debe ser particularmente estricta en los casos en los que el fuero alternativo elegido sea precisamente el del actor. El Abogado General Jacobs, en las Conclusiones ${ }^{42}$ presentadas el 16 de septiembre de 2004, mantiene que las salvedad en favor de los órganos jurisdiccionales «del lugar en el que esté domiciliada la parte demandante - a lo que, por regla general, es contrario el Convenio-, resulta particularmente excepcional». Invoca la doctrina del TJUE conforme a la cual tales excepciones deben interpretarse de 'manera estricta'43.

${ }^{40}$ Conclusión 33: «Según jurisprudencia reiterada del Tribunal de Justicia, debido al carácter general del principio contenido en el artículo 2, las excepciones al mismo deben interpretarse de manera restrictiva. Lo mismo cabe decir, naturalmente, del artículo 5, que permite que las personas domiciliadas en un Estado contratante puedan ser demandadas ante los tribunales de otro Estado contratante. La exigencia de una interpretación restrictiva significa que las reglas de competencia del artículo 5 no pueden aplicarse analógicamente, de manera que rijan en otros casos, además de los previstos por el Convenio de Bruselas. En la sentencia Dumez France y Tracoba, el Tribunal de Justicia señala que debe aplicarse este principio, tanto más cuanto que el Convenio de Bruselas permite interponer la demanda ante los tribunales del Estado contratante en el que esté domiciliado el demandante. Efectivamente, según el Tribunal de Justicia, aparte de los casos expresamente previstos, del Convenio de Bruselas se deduce una clara oposición a atribuir competencia a los tribunales del domicilio del demandante».

${ }^{41}$ Cfr. conclusión 34.

42 Asunto C-464/01, Johann Gruber contra Bay Wa AG.

${ }^{43}$ En especial cfr. la conclusión 31. Así lo ha señalado el TJUE específicamente en relación con los artículos 13 y ss. del texto de Bruselas que se corresponden con los arts. 15 y ss. del Reglamento y del Convenio. 
Refuerza esta idea la jurisprudencia del propio TJUE que, en contraste con lo expuesto respecto de las excepciones de competencia especial, se inclina por una 'interpretación amplia' de los preceptos que contienen una excepción de competencia exclusiva, precisamente para evitar el forumshopping. La jurisprudencia mencionada es recogida por el Abogado General Geelhoed, en las Conclusiones ${ }^{44}$ presentadas el 16 de septiembre de 2004. Tras reconocer en ellas ${ }^{45}$ que el art. 16.4 del Convenio de Bruselas (= art. 22.4 del Reglamento y del Convenio, es decir, validez de patentes), constituye una excepción al principio general actor rei forum sequitur, y que según jurisprudencia reiterada del TJUE las excepciones deben ser objeto de una interpretación restrictiva, concluye sin embargo con la propuesta de que aquel precepto sea objeto de una interpretación amplia. Las razones ofrecidas son "favorecer la seguridad jurídica», "disminuir el riesgo de resoluciones contradictorias» y «excluir la posibilidad del $f_{o-}$ rumshopping» ${ }^{46}$. Esto es, las mismas que justifican la interpretación estricta de las competencias especiales.

El Reglamento (CE) 593/2008 del Parlamento Europeo y del Consejo, de 17 de junio de 2008, trata sobre la ley aplicable a las obligaciones contractuales ${ }^{47}$ que, aunque sea de forma indirecta, afecta a la competencia territorial. Esto es, el juez ante el que se presenta una demanda debe examinar su propia competencia, para lo que resulta indispensable determinar cual es el lugar de cumplimiento de la obligación contractual, lo que implica establecer previamente, conforme a sus normas de conflicto, la ley que resulta aplicable a esa obligación. Dada la extraordinaria importancia de las obligaciones contractuales resulta obligado un breve comentario a esta cuestión.

Ante todo debe recordarse que la materia contractual es la primera de las competencias especiales, prevista en el art. 5.1 del Reglamento y del Convenio, que ya estaba contemplada en el texto de Bruselas. Sin embargo, lo cierto es que esa materia ha proporcionado desde entonces una fuente ingente de dudas. Las Conclusiones de los Abogados Generales, que han debido informar asuntos sobre obligaciones contractuales, dejan constancia reiterada de la dificultad: «la noción de lugar de cumplimiento de una obligación, aparentemente

${ }^{44}$ Asunto C-4/03, Gesellschaft für Antriebstechnik mbH \& Co. KG (GAT) contra Lamellen und Kupplungsbau Beteiligungs KG (LuK), sobre petición de decisión prejudicial planteada por el Oberlandesgericht Düsseldorf de Alemania.

${ }^{45}$ Cfr. conclusión 4.

${ }^{46}$ Cfr. conclusión 5.

${ }^{47}$ DO L 177 de 4.7.2008, p. 6 ss. 
sencilla, se revela pronto como una rica fuente de interrogantes: ¿qué ha de entenderse por 'materia contractual'? ¿De qué obligación se trata? ¿De la de entregar la cosa o realizar la prestación, por ejemplo, o de la de pagar el precio? ¿Cómo se determina el lugar de cumplimiento? ¿De acuerdo con qué derecho? ¿Con el del foro? ¿Con qué otro?» ${ }^{48}$.

Efectivamente, la competencia especial por razón de la materia contractual arroja sobre el juez que conozca del asunto una serie de responsabilidades extraordinariamente complejas para comprobar su propia competencia: debe determinar el derecho aplicable; aplicarlo para establecer el lugar de cumplimiento de la obligación; concluir si la obligación está o no sujeta a un régimen internacional uniforme; etc. Hay que tener en cuenta además que la casuística en materia contractual es amplísima y resultan constantes las cuestiones prejudiciales sobre aspectos muy difíciles de prever. Hay casos si no extravagantes sí inverosímiles. Por ejemplo, el Bundesgerichtshof alemán plantea el 19 de mayo de 2008 cuál debe considerarse el lugar de cumplimiento de una obligación relativa a los vuelos aéreos entre dos Estados ${ }^{49}$.

En este estado de cosas el Reglamento (CE) 593/2008 renueva la legislación sobre el particular y busca favorecer la previsibilidad de los litigios. El primer criterio de determinación de la ley aplicable será la elegida por los contratantes y, en su defecto, la determina con cargo a unos criterios específicos para cada tipo particular de contrato. Si el contrato no puede catalogarse como uno de los tipos específicos, o si sus elementos corresponden a más de uno de los tipos especificados, «debe regirse por la ley del país donde tenga su residencia habitual la parte que deba realizar la prestación característica del contrato. En el caso de un contrato cuyo objeto sea un conjunto de derechos y obligaciones que pueda catalogarse como correspondiente a más de uno de los tipos especificados de contrato, la prestación característica del contrato debe determinarse en función de su centro de gravedad $\aleph^{50}$. Si el contrato en cuestión tiene una relación muy estrecha con otro contrato o contratos, se prevén 'cláusulas de escape ${ }^{51}$. Solo consideraciones de interés público justifican,

${ }^{48}$ Conclusión 26 del Abogado General Sr. Dámaso Ruiz-Jarabo Colomer presentada el 16 de marzo de 1999 en el Asunto C-440/97, G.I.E groupe Concorde y otros contra el Capitán del buque 'Suhadiwarno Panja' y otros.

${ }^{49}$ Asunto C-204/08, Peter Rehder contra Air Baltic Corporation, publicado en DO C 197 de 02.08.2008, p. 11 ss.

${ }^{50}$ Considerando 19 del Reglamento 593/2008.

${ }^{51}$ Considerando 21 del Reglamento 593/2008. 
en circunstancias excepcionales, el recurso a excepciones basadas en el orden público y en leyes de policía ${ }^{52}$.

\section{EXCEPCIONES EN EL DERECHO ESPAÑOL}

El art. 22 LOPJ contempla los supuestos en los que son competentes en el orden civil los órganos jurisdiccionales españoles. Aunque con una distribución topográfica distinta a la regulación comunitaria, también aquí se puede adivinar un esquema mas o menos similar en el tratamiento de las excepciones al principio actor rei forum sequitur, en el que se distinguen las competencias exclusivas de las especiales. A ellas se añaden unas competencias que, podríamos denominar, de carácter subsidiario tanto en cuanto se aplican en defecto tanto de los criterios generales como de los exclusivos.

En mi opinión, estas competencias territoriales de carácter subsidiario se justifican por la concurrencia de dos factores: a) porque la mayoría de ellas afectan a materias de 'ley personal' que están excluidas de los convenios ${ }^{53}$ de la UE a los que hemos hecho referencia; b) porque en la generalidad de los casos refuerzan el principio actor rei forum sequitur al incorporar el criterio de la 'residencia habitual en España', lo que hace menos necesaria su distinción con el 'domicilio'.

De esta forma, puede decirse que en el orden civil, los Juzgados y Tribunales españoles serán competentes:

A. Con carácter general: por sumisión expresa o tácita de las partes o en aplicación del principio actor rei forum sequitur cuando el demandado tenga su domicilio en España (art. 22.2 LOPJ).

B. Con carácter exclusivo ${ }^{54}$ : por razón de las cinco materias de competencia exclusiva española recogidas en art. 22.1 LOPJ. Este

${ }^{52}$ Considerando 37 del Reglamento 593/2008.

${ }^{53} \mathrm{El}$ art. 1.2 del Convenio de 30.10.2007 excluye de su ámbito de aplicación: «a) el estado y la capacidad de las personas físicas, los regímenes matrimoniales, los testamentos y las sucesiones; b) la quiebra, los procedimientos de liquidación de empresas o de otras personas jurídicas insolventes, los convenios entre quebrado y acreedores y demás procedimientos análogos; c) la seguridad social; d) el arbitraje».

${ }^{54}$ Las materias de competencia territorial exclusiva española son las relativas a: a) derechos reales y arrendamientos de inmuebles que se hallen en España; b) constitución, validez, nulidad o disolución de sociedades o personas jurídicas que tengan su domicilio en territorio español, así como respecto de los acuerdos y decisiones de sus órganos; c) validez o nulidad de las inscripciones practicadas en un Registro español; d) inscripciones o de validez de patente y otros derechos sometidos a depósito o re- 
precepto se inspira directamente en el art. 16 del Convenio de Bruselas, que luego ha pasado al art. 22 tanto en el Reglamento 44/2001 como en el Convenio de Lugano de 2007. Esas materias vienen constituidas por los derechos reales, algunos aspectos fundamentales de las personas jurídicas, inscripciones registrales, patentes y ejecución de resoluciones. Contra lo sostenido por algún autor, no puede negarse que el criterio seguido por el legislador español es de numerus clausus, que mimetiza, en la forma y en el fondo, el criterio del legislador europeo.

C. Con carácter subsidiario ${ }^{55}$ : por conducto del art. 22.3 LOPJ que instaura, con esta naturaleza subsidiaria, la competencia territorial española en diez materias que afectan, sobre todo, a aspectos relativos al estado y a la capacidad de las personas físicas, a los regímenes matrimoniales, a los testamentos y a las sucesiones. La subsidiariedad se opera exclusivamente respecto de los fueros generales y de los exclusivos. Sin embargo, en la práctica, la regla actor rei forum sequitur determinará previamente la competencia de los tribunales españoles para la generalidad de los supuestos ahora contemplados. Éstos no se encuentran recogidos en los convenios y reglamentos comunitarios antes mencionados pues, como ya he dicho, exceden su

gistro cuando se hubiere solicitado o efectuado en España el depósito o registro; e) de reconocimiento y ejecución en territorio español de resoluciones judiciales y decisiones arbitrales dictadas en el extranjero.

${ }^{55}$ Las materias de competencia territorial subsidiaria española son las relativas a: a) declaración de ausencia o fallecimiento, cuando el desaparecido hubiere tenido su último domicilio en territorio español; b) incapacitación y de medidas de protección de la persona o de los bienes de los menores o incapacitados, cuando éstos tuviesen su residencia habitual en España; c) relaciones personales y patrimoniales entre cónyuges, nulidad matrimonial, separación y divorcio, cuando ambos cónyuges posean residencia habitual en España al tiempo de la demanda o el demandante sea español y tenga su residencia habitual en España, así como cuando ambos cónyuges tengan la nacionalidad española, cualquiera que sea su lugar de residencia, siempre que promuevan su petición de mutuo acuerdo o uno con el consentimiento del otro; d) filiación y de relaciones paternofiliales, cuando el hijo tenga su residencia habitual en España al tiempo de la demanda o el demandante sea español o resida habitualmente en España; e) constitución de la adopción, cuando el adoptante o el adoptado sea español o resida habitualmente en España; f) alimentos, cuando el acreedor de los mismos tenga su residencia habitual en territorio español; g) de obligaciones contractuales, cuando éstas hayan nacido o deban cumplirse en España; h) obligaciones extracontractuales, cuando el hecho del que deriven haya ocurrido en territorio español o el autor del daño y la víctima tenga su residencia habitual común en España; i) en las acciones relativas a bienes muebles, si éstos se encuentran en territorio español al tiempo de la demanda; j) sucesiones, cuando el causante haya tenido su último domicilio en territorio español o posea bienes inmuebles en España (art. 22.3 LOPJ). 
ámbito de aplicación, salvo algunos casos concretos como lo son las reclamaciones de alimentos, de obligaciones cuasidelictuales y de las obligaciones contractuales cuando éstas hayan nacido o deban cumplirse en España. Estas últimas excepciones han estado y están previstas en el art. 5 de los Convenios de Bruselas y Lugano (1988 y 2007) y del Reglamento 44/2001, si bien en la categoría de competencias especiales. Como ya he expuesto, el Reglamento 593/2008 ha resuelto los problemas que suscitaba la cuestión de la competencia territorial para conocer de los casos de obligaciones contractuales, al pormenorizar reglas específicas para cada tipo de contrato y, en su defecto, introducir los criterios que la atribuyen al lugar de residencia del obligado o, en última instancia, al lugar donde radique el 'centro de gravedad' del contrato.

D. Con carácter especial ${ }^{56}$ : conforme al art. 22.4 y 5 LOPJ pertenecen a esta categoría algunos contratos (consumo, prestación de servicios y seguros) así como los casos de explotación de sucursal y medidas provisionales y de aseguramiento. Mención aparte merece la materia concursal, en la que la LOPJ se remite a su ley reguladora ${ }^{57}$, cuyo art. 10.1 abandona el criterio del domicilio del deudor (actor rei forum sequitur) y acoge el del lugar en el que se encuentre el «centro de sus intereses principales».

Si el art. 22.2 LOPJ establece que en el orden civil los Juzgados y Tribunales españoles serán competentes con carácter general cuando el demandado tenga su domicilio en España, la LEC ordena con carácter particular la competencia territorial y determina definitiva-

${ }^{56}$ Las materias de competencia territorial especial española son las relativas a: a) contratos de consumidores, cuando el comprador tenga su domicilio en España si se trata de una venta a plazos de objetos muebles corporales o de préstamos destinados a financiar su adquisición; b) cualquier otro contrato de prestación de servicio o relativo a bienes muebles, cuando la celebración del contrato hubiere sido precedida por oferta personal o de publicidad realizada en España o el consumidor hubiera llevado a cabo en territorio español los actos necesarios para la celebración del contrato; c) seguros, cuando el asegurado y asegurador tengan su domicilio habitual en España; d) litigios relativos a la explotación de una sucursal, agencia o establecimiento mercantil, cuando éste se encuentre en territorio español; y e) medidas provisionales o de aseguramiento respecto de personas o bienes que se hallen en territorio español y deban cumplirse en España.

${ }^{57} \mathrm{El}$ art. 10.1 de la Ley Concursal, al regular la competencia internacional y territorial, dice: «La competencia para declarar y tramitar el concurso corresponde al juez de lo mercantil en cuyo territorio tenga el deudor el centro de sus intereses principales. Si el deudor tuviese además en España su domicilio y el lugar de éste no coincidiese con el centro de sus intereses principales, será también competente, a elección del acreedor solicitante, el juez de lo mercantil en cuyo territorio radique aquél». 
mente el órgano jurisdiccional español competente. Aquel precepto, junto con las disposiciones reglamentarias de la UE, simplemente observa cuando los órganos jurisdiccionales españoles son o pueden ser competentes. La designación del Juzgado o Tribunal específico competente dentro de España se determina conforme a las normas contenidas en la LEC.

Así, el principio actor rei forum sequitur se corresponde con lo dispuesto en los arts. 50.1 y 51.1 LEC que sitúan el fuero general de las personas físicas y jurídicas en el del domicilio de cada una de ellas. Y los entes sin personalidad podrán ser demandados en el domicilio de sus gestores o en cualquier lugar en que desarrollen su actividad. La exégesis de este principio y de sus excepciones ofrece, aparentemente, una menor dificultad para el derecho interno español. La jurisprudencia del Tribunal Supremo que lo interpreta se pronuncia a favor de la competencia general de los órganos jurisdiccionales del domicilio del demandado ${ }^{58}$ - con las salvedades prevenidas en la LEC y en LOPJ_ de conformidad con las razones legales e históricas que imponen la aplicación del principio.

La competencia territorial civil ha estado informada, en la tradición jurídica, por normas de naturaleza dispositiva. Aún hoy se considera asi ${ }^{59}$. Sin embargo, los supuestos de improrrogabilidad y de indisponibilidad son cada vez más numerosos e importantes. Entre ellos destacan, precisamente, las excepciones a nuestro principio recogidas en el art. 52 LEC, contempladas desde el art. 54.1 LEC, tanto en cuanto atribuye carácter imperativo a las alteraciones del fuero contenidas en las reglas establecidas en los ordinales $1 .^{\circ}$ y $4 .^{\circ}$ a $15 .^{\circ}$ del apartado 1 y en el apartado 2 del primer artículo. De tal forma que, en teoría, el ámbito dispositivo de aquellas excepciones queda reducido al art. 52.1.2. ${ }^{\circ}$ y $3 .^{\circ}$ LEC, esto es, a las demandas sobre presentación y aprobación de las cuentas que deban dar los administradores de bienes ajenos, y a las relativas a obligaciones de garantía o complemento de otras anteriores.

Si prescindimos de los casos de acumulación de acciones y de pluralidad de demandados, el carácter imperativo atribuido a las reglas

${ }^{58}$ STS 1. a de 22 marzo 1991: «... competencia del domicilio del demandado y en conformidad, a su vez, con la realidad actual y tradición histórica representada por los principios non reus actoris, sed actor reí forum sequitur y actor rei forum sequitur (el demandado no debe seguir el fuero del actor, sino éste el de aquél)».

${ }^{59}$ Cfr. entre otros muchos el ATS 11075/2008 de 16.10.2008, FJ 2, sobre el «carácter dispositivo que tienen, en general, las normas sobre competencia territorial (artículos 54 y 59 LEC)». 
citadas del art. 52 LEC excepcionan el fuero general actor rei forum sequitur, al tiempo que excluyen los fueros convencionales (tácitos o expresos), en los siguientes supuestos: a) forum rei sitae; b) cuestiones hereditarias; c) asistencia o representación de incapaces, incapacitados o declarados pródigos; d) materia de derecho al honor, a la intimidad personal y familiar y a la propia imagen y, en general, en materia de protección civil de derechos fundamentales; e) arrendamientos de inmuebles y en los de desahucio; f) propiedad horizontal; g) indemnización de los daños y perjuicios derivados de la circulación de vehículos de motor; h) impugnación de acuerdos sociales; i) infracciones de la propiedad intelectual; j) competencia desleal; k) patentes y marcas; l) acciones para que se declare la no incorporación al contrato o la nulidad de las cláusulas de condiciones generales de la contratación; $\mathrm{m}$ ) tercerías de dominio o de mejor derecho que se interpongan en relación con un procedimiento administrativo de apremio; y n) litigios en materia de seguros, ventas a plazos de bienes muebles corporales y contratos destinados a su financiación, así como en materia de contratos de prestación de servicios o relativos a bienes muebles cuya celebración hubiera sido precedida de oferta pública (art. 52.1.1. ${ }^{\circ}$ y $4 .^{\circ}$ a $15 .^{\circ}$ y 2 LEC).

Todavía cabría sumar, a estas reglas imperativas, otras disposiciones de competencia territorial, también imperativas, diseminadas por la LEC sobre procesos matrimoniales y de menores (arts. 769, 777, 779, 807), así como las derivadas de la especialidad del juicio (monitorio ${ }^{60}$ : art. 813, y cambiario: art. 820) que se completan con la exclusión de sumisión territorial en los procesos verbales (art. 54).

Tanto los fueros convencionales como los legales especiales desplazan el principio actor rei forum sequitur, por constituir excepciones al mismo. Pero solo los últimos - y siempre que sean improrrogables conforme a lo antes expuesto- pueden y deben ser apreciados de oficio por los Tribunales. Por el contrario, los juzgadores solo podrán operar a instancia de parte sobre los cánones de competencia territorial de naturaleza dispositiva. El art. 54.1 LEC contiene, a este respecto, la norma básica de competencia territorial conforme a la cual las reglas legales atributivas de esa competencia sólo se aplicarán en defecto de sumisión expresa o tácita de las partes a los tribunales de una determinada circunscripción. Como dice la STS 4. ${ }^{a}$ de 10 de mayo de 2006 «únicamente dejará de aplicarse esta regla en los casos

${ }^{60}$ AATS 1. ${ }^{\text {a } 11075 / 2008}$ de 22.10.2008, 8778/2008 de 16.10.2008, 8776/2008 de 15.10.2008, 9803/2008 de 08.10.2008, 8806/2008 de 07.10.2008, 10005/2008 de 30.09.2008, 10003/2008 de 26.09.2008. 
en que la ley reconozca explícitamente el carácter imperativo del precepto que regule la competencia territorial en un determinado proceso, ... Por consiguiente, para afirmar que una disposición reguladora de competencia territorial puede ser aplicada de oficio por el Juez, a pesar de que nadie haya formulado alegación alguna en contra de tal competencia o, incluso, a pesar de haberse sometido tácitamente las partes a la Jurisdicción de ese Juez, es de todo punto necesario que la ley haya reconocido de forma expresa y clara el carácter imperativo de aquélla disposición. Si no existe ese reconocimiento legal expreso, entra en juego la regla general primeramente mencionada, y no es posible declarar de oficio la falta de competencia por razón del territorio» ${ }^{61}$.

Sin embargo - y es aquí donde se produce la paradoja- a pesar del declarado carácter imperativo de la mayoría de las excepciones al principio actor rei forum sequitur, la infracción de las mismas no es suficiente para fundar legalmente un incidente de nulidad, pues, como a continuación explicaré, no contemplan tal posibilidad ni el art. 225.1 LEC ni el art. 238.1 LOPJ.

\section{UNA POSIBLE SOLUCIÓN}

En otras palabras, la violación de cualquiera de esas reglas imperativas que excepcionan el principio actor rei forum sequitur no está sancionada con la nulidad del acto infractor. Tanto el art. 225.1 LEC como el art. 238.1 LOPJ solo consideran nulos de pleno derecho los actos que «se produzcan por o ante tribunal con falta de jurisdicción o de competencia objetiva o funcional». En ese mismo sentido el art. 48.2 LEC solo asocia la declaración de nulidad a la falta de competencia objetiva. La referencia explícita a la competencia objetiva o funcional excluye la competencia territorial. Dado el carácter restrictivo que debe presidir la interpretación de las causas de nulidad, no es posible su extensión a supuestos no previstos en ellas. Por lo que aquellas normas que excepcionan el principio actor rei forum sequitur, a pesar de su carácter imperativo, deben ser consideradas

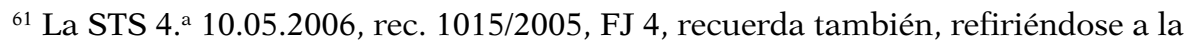
interpretación del art. 10.1 LPL, que «la competencia o incompetencia por razón del territorio no puede ser apreciada de oficio por los Jueces y Tribunales del orden social de la jurisdicción, ha sido declarado por nuestras sentencias de 16 de febrero de 2004 (recurso 3210/2002), 15 de septiembre de 2004 (recurso 1353/2003), 21 de octubre de 2004 (recurso 4546/2002), 4 de noviembre de 2004 (recurso 4507/2002), 16 de noviembre de 2004 (recurso 363/2003) y otras». 
menos perfectas, con todas las consecuencias que se desprenden de tal calificación.

Sin embargo, esta problemática empieza a ser resuelta por la jurisprudencia con una respuesta de cuya idoneidad no estoy seguro. La respuesta consiste en atribuir a esos casos de fuero territorial imperativo un tratamiento "semejante al dispensado a la competencia objetiva, ya que sus normas especificas, carecen del carácter dispositivo que tienen, en general, las normas sobre competencia territorial ${ }^{62}$. Esta doctrina está absolutamente consolidada y es reiteradísima. Por citar solo las resoluciones más recientes véanse en este sentido los AA TS de la Sala Primera 11075/2008 de 22 octubre 2008, $8778 / 2008$ de 16 octubre 2008, 8776/2008 de 15 octubre 2008, $9803 / 2008$ de 08 octubre $2008,8806 / 2008$ de 07 octubre 2008, $10005 / 2008$ de 30 septiembre 2008, 10003/2008 de 26 septiembre 2008 , etc.

Pero esta opinión jurisprudencial nació circunscrita a un caso muy concreto de competencia territorial aplicable al proceso monitorio determinada por el artículo 813 LEC, que contiene un fuero de naturaleza imperativa, por lo que el TS ha establecido el criterio según el cual «cuando el domicilio que consta en la demanda no se corresponde con el actual que ha quedado acreditado por hechos de conocimiento posterior debe aplicarse analógicamente la regla prevenida por el artículo 48 de la Ley de Enjuiciamiento Civil para la falta de competencia objetiva» ${ }^{63}$. Sin embargo esa extensión analógica - desde ese supuesto específico al que se le aplican reglas de competencia objetiva aún cuando es un problema de competencia territorial-, es muy dudoso que pueda aplicarse también desde las causas de nulidad por falta de competencia objetiva, y extenderlas a las de falta de competencia territorial, por mucho que ésta sea imperativa.

A pesar de esta duda, hay ya una resolución de la Sala Primera del TS que ha optado por esa insegura dirección. Se trata del ATS 6803/2004 de 25 de mayo 2004. El auto citado, a efectos de la declaración de nulidad, considera justificada la extensión analógica de las normas de la falta de competencia objetiva a la falta de competencia territorial, según argumenta "para evitar actuaciones procesales incompetenciales y cuando esto sucede el recurso de nulidad de actuaciones de oficio (artículo 238 de la Ley Orgánica del Poder Ju-

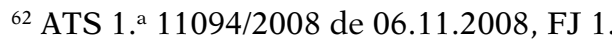

${ }^{63}$ Último lugar citado. 
dicial) es el procedente y al que se debe acudir para restablecer la legalidad del proceso" ${ }^{64}$.

No obstante lo razonado y resuelto en ese auto, con las leyes en la mano, lo cierto es que lo actuado con falta de competencia territorial (imperativa o no), a diferencia de lo que sucede con la falta de competencia objetiva, ni provoca la nulidad de pleno derecho, ni - como acertadamente informó el Fiscal en ese caso- «implica una violación al Juez predeterminado por la ley como se infiere de su exclusión como motivo del recurso extraordinario por infracción procesal en el artículo 469.1.1 ${ }^{\circ}$ LEC que sólo comprende la infracción de las normas sobre jurisdicción y competencia objetiva o funcional».

La analogía es un método de integración esgrimible contra las denominadas lagunas de la ley. Por lo que se comparta o no la tesis sobre la procedencia de realizar aquella ampliación analógica, es conveniente modificar en todo caso los preceptos afectados (los arts. 48 y 225.1 LEC y 238.1 LOPJ). Si se considera que la infracción de las normas imperativas sobre competencia territorial debe estar sancionada con la nulidad, la ley debe establecerlo así expresamente. Y si se estima lo contrario, la ley debe pronunciarse en términos tales que impidan la interpretación realizada por el TS.

${ }^{64}$ ATS 1. ${ }^{\text {a } 6803 / 2004 ~ d e ~ 25.05 .2004, ~ F J ~} 1$. 